\title{
Control of Vaporous Naphthalene by Scrubbing with Surfactants
}

\author{
Chih-Cheng $\mathrm{Wu}^{1}$ and Whei-May Grace Lee ${ }^{2}$
}

\begin{abstract}
This study investigates the effects of adding anionic and nonionic surfactants to the scrubbing liquid during the absorption of naphthalene (Nap) using a wet scrubber. Both batch and continuous experiments were performed on a laboratory-scale packed tower scrubber by adding surfactants to the scrubbing liquid. An anionic surfactant sodium dodecyl sulfate (SDS) and two nonionic polyoxyethylene surfactants $\mathrm{C}_{10} \mathrm{E}_{4}$ [tetraethylene glycol mono(decyl ether)] and $\mathrm{C}_{14} \mathrm{E}_{8}$ [octaethylene glycol mono(tetradecyl ether)] were used. The concentrations of the surfactant solutions all exceeded the critical micelle concentration. The results of continuous experiments indicate that the efficiencies of removal of naphthalene by $\mathrm{C}_{10} \mathrm{E}_{4}$ and $\mathrm{C}_{14} \mathrm{E}_{8}$ were 75.0 and $71.9 \%$, respectively, at a concentration of $1.0 \times 10^{-2} \mathrm{M}$. The removal efficiency of naphthalene by SDS ranged from 6 to $39 \%$ at concentrations from $1.0 \times 10^{-2}$ to $1.0 \times 10^{-1} \mathrm{M}$ under continuous scrubbing. In the batch experiments, the batch naphthalene absorption capacities were estimated to be $31.8 \mu \mathrm{g} \mathrm{Nap} / \mathrm{g} \mathrm{C}_{10} \mathrm{E}_{4}, 12.9 \mu \mathrm{g} \mathrm{Nap}_{\mathrm{g} \mathrm{C}} \mathrm{C}_{14} \mathrm{E}_{8}$, and $2.4 \mu \mathrm{g}$ Nap/g SDS. A comparison was also made among SDS, $\mathrm{C}_{10} \mathrm{E}_{4}$, and $\mathrm{C}_{14} \mathrm{E}_{8}$ in terms of cost, foaming, impact of wastewater, removal efficiency, and absorption capacity.
\end{abstract}

DOI: 10.1061/(ASCE)0733-9372(2004)130:3(276)

CE Database subject headings: Surface-active agents; Hydrocarbons; Scrubbers; Absorption; Air pollution.

\section{Introduction}

Municipal and hazardous waste incinerators are extensively used to dispose of solid waste. However, the combustion of waste generates toxic air pollutants, including polycyclic aromatic hydrocarbons (PAHs). Some PAHs are known to be carcinogenic and mutagenic (You et al. 1994). Therefore, the emission of PAHs from incinerators has received considerable attention over recent years. The predominant PAH compound in the gas phase of flue gas is naphthalene (Nap), which represents over $60 \%$ of all the PAHs in the gas phase of the flue gas from municipal waste incinerators and industrial stacks (Yang et al. 1998). Consequently, naphthalene was selected as the representative PAH compound experimentally examined herein. Polycyclic aromatic hydrocarbons are semivolatile hydrophobic organic compounds (HOCs). Current technologies for controlling PAHs include activated carbon absorption, catalytic combustion, and thermal oxidation. However, the equipment for performing these processes is often ancillary control equipment installed in municipal waste and other incinerators. Only a few studies have addressed the development of technology based on existing equipment for controlling PAHs, to reduce cost and simplify the control system, facilitating its operation and maintenance.

${ }^{1} \mathrm{PhD}$ Candidate, Graduate Institute of Environmental Engineering, National Taiwan Univ., 71, Chou-Shan Rd., Taipei 106, Taiwan, R.O.C.

${ }^{2}$ Professor, Graduate Institute of Environmental Engineering, National Taiwan Univ., 71, Chou-Shan Rd., Taipei 106, Taiwan, R.O.C.

Note. Associate Editor: Joseph D. Wander. Discussion open until August 1, 2004. Separate discussions must be submitted for individual papers. To extend the closing date by one month, a written request must be filed with the ASCE Managing Editor. The manuscript for this paper was submitted for review and possible publication on September 6, 2002; approved on July 22, 2003. This paper is part of the Journal of Environmental Engineering, Vol. 130, No. 3, March 1, 2004. CASCE, ISSN 0733-9372/2004/3-276-281/\$18.00.
Surfactants are composed of hydrophobic and hydrophilic segments. When a surfactant solution is at low concentration, some surfactant molecules disperse in solution and some are present at the interface between the gas and liquid phases. Micelles are formed when the surfactant concentration reaches a threshold. The threshold concentration is called the critical micelle concentration (CMC) (Rosen 1989). In aqueous solutions, the hydrophobic ends of the surfactant molecules are concentrated at the micelles' inner cores while the hydrophilic ends are at the surface. The inner cores of the micelles can dissolve HOCs (Doong et al. 1996; Butler and Hayes 1998).

The application of surfactants to increase the solubility of PAHs has been comprehensively investigated in recent years. However, the removal of vaporous PAHs in flue gas from municipal waste incinerators has not yet been studied. Liu et al. (1991) and Zheng and Obbard (2002) determined that the solubility of PAHs increases with surfactant concentration at a contaminated soil site when the concentration of surfactant exceeds the CMC. Shiau et al. (2000) and Zheng and Obbard (2000) employed food grade nonionic surfactants to remove chlorinated solvents and PAHs from soil. Bai et al. (2001) developed a process to extract PAHs in aqueous solution using the nonionic surfactant Tergitol 15-S-7, in a process called cloud point extraction. Tiehm et al. (1997) showed that surfactants can alter partitioning and that adding nonionic surfactants increases the amount of PAHs in the liquid phase (Arkopal N-300 and Sapogenat T-300). Edwards et al. (1991, 1992) used four polyoxyethylene nonionic surfactants (Brij 30, Igepal CA-720, Tergitol NP-10, and Triton X-100) to elucidate the solubility of PAHs in soil experiments at surfactant concentrations above and below the CMC. They reported that nonionic surfactants increase the solubility of PAHs above the CMC. Paterson et al. (1999) and Yeom et al. (1995) used an anionic surfactant at a concentration above the CMC to improve extraction from coal-tar-permeated land. Link (2000) claimed that partition coefficients increased with the number of rings in the $\mathrm{PAH}$ structure in a nonionic surfactant solution. Huang and Lee 
Table 1. Molecular Weight and Critical Micelle Concentration of Surfactants

\begin{tabular}{|c|c|c|}
\hline Surfactant & Molecular weight $(\mathrm{g})$ & Critical micalle concentration $(\mathrm{M})$ \\
\hline Anionic surfactant & & $8.2 \times 10^{-3}\left(25^{\circ} \mathrm{C}\right)($ Rosen 1989$)$ \\
\hline Sodium dodecyl sulfate & 288.4 & $\begin{array}{l}8.6 \times 10^{-3}\left(40^{\circ} \mathrm{C}\right)(\text { Rosen 1989) } \\
8.01 \times 10^{-3}\left(25^{\circ} \mathrm{C}\right)(\text { Clarke et al. } 1993) \\
7.98 \times 10^{-3}\left(25^{\circ} \mathrm{C}\right)(\text { Doong et al. 1996) }\end{array}$ \\
\hline \multicolumn{3}{|l|}{ Nonionic surfactant } \\
\hline Tetraethylene glycol mono(decyl ether) $\left(\mathrm{C}_{10} \mathrm{E}_{4}\right)$ & 334.5 & $4.9 \times 10^{-4}\left(50^{\circ} \mathrm{C}\right)($ Chen et al. 1998$)$ \\
\hline Octaethylene glycol mono(tetradecyl ether) $\left(\mathrm{C}_{14} \mathrm{E}_{8}\right)$ & 566.8 & $7.3 \times 10^{-6}\left(50^{\circ} \mathrm{C}\right)($ Chen et al. 1998$)$ \\
\hline
\end{tabular}

(2002) considered the enrichment factor in performing enhanced removal of vaporous naphthalene by the anionic surfactant sodium dodecyl sulfate (SDS). Vipulanandan and Ren (2000) described the enhanced solubility and biodegradation of naphthalene using anionic and nonionic surfactants. Yeom et al. (1996) posited that micelles have an enhanced effect on the solubility of PAHs. Liu and Roy (2000) presented a model to determine a surfactant's micelle-water distribution coefficients of aromatic hydrocarbons. Guha et al. (1998a, b) and An et al. (2002) considered three PAHs (naphthalene, phenanthrene, and pyrene) that were partitioned between surfactant solution and micelles. According to their results, hydrophobic PAHs dissolve in the core of micelles such that the volume of the core changes, increasing the solubility of the more hydrophobic PAHs.

Currently, packed scrubbers are often used to control acidic gases, such as $\mathrm{HCl}$, in the flue gas from municipal incinerators. However, little work has been conducted on the removal of vaporous PAHs using wet scrubbers. This study investigates the efficiency of removal of vaporous naphthalene using a wet scrubber, by adding anionic and nonionic surfactants to the scrubbing liquid. The wet scrubber used herein is a laboratory-scale packed tower, designed and made with the characteristics of the packed tower operated at a municipal incinerator in Taiwan. Huang (2001) conducted batch experiments on the enhancement of the solubility of naphthalene, using three surfactants, including the anionic surfactant SDS and the nonionic surfactants $\mathrm{C}_{10} \mathrm{E}_{4}$ and $\mathrm{C}_{14} \mathrm{E}_{8}$. Several useful data on these three surfactants were obtained. Therefore, three surfactants (SDS, $\mathrm{C}_{10} \mathrm{E}_{4}$, and $\mathrm{C}_{14} \mathrm{E}_{8}$ ) were selected to clarify the effects of adding surfactants on the removal of vaporous naphthalene using a wet scrubber.

\section{Materials and Method}

\section{Chemicals}

Naphthalene was purchased from Merck (minimum purity 99\%). Sodium dodecyl sulfate was the anionic surfactant (Merck, purity $>99 \%$ ). Tetraethylene glycol mono(decyl ether) $\left[\mathrm{CH}_{3}\left(\mathrm{CH}_{2}\right)_{9}\left(\mathrm{OCH}_{2} \mathrm{CH}_{2}\right)_{4} \mathrm{OH}\right]\left(\mathrm{C}_{10} \mathrm{E}_{4}\right)$ and octaethylene glycol mono(tetradecyl ether) $\left[\mathrm{CH}_{3}\left(\mathrm{CH}_{2}\right)_{13}\left(\mathrm{OCH}_{2} \mathrm{CH}_{2}\right)_{8} \mathrm{OH}\right]\left(\mathrm{C}_{14} \mathrm{E}_{8}\right)$ were selected as the nonionic surfactants. They were purchased from Nikko Chemical Co. and were at least $99 \%$ pure. Table 1 presents the properties of the above surfactants, including their molecular weights and CMCs.

\section{Experimental System}

As depicted in Fig. 1, the experimental system comprises three parts-a standard naphthalene gas generation subsystem, a packed tower scrubber, and a naphthalene sampling analysis sub- system. Pure compressed nitrogen was the carrier gas used to generate a standard concentration of vaporous naphthalene, and its flow was controlled using a mass flow controller (Sierra, SideTrak Mode 860). The flow rate of nitrogen was maintained at 10 $\mathrm{L} / \mathrm{min}$ and standard temperature and pressure STP. A diffusion tube (VICI Metronics Co.) was filled with solid naphthalene and immersed in a water bath (Deng-Yng Co., ZC-4000, $\pm 0.1^{\circ} \mathrm{C}$ ) with a temperature controller. The concentration of gaseous naphthalene was regulated by the nitrogen flow rate and the temperature of the water bath. The temperature of the gas stream was $45.0^{\circ} \mathrm{C}$. A switch valve was operated to enable the flow of standard naphthalene gas through the scrubber or gas sampling bulbs (Supelco, 1,000 mL). When the flow of standard naphthalene approached the steady state, the Teflon stopcock plug of the gassampling bulb was closed to check the concentration of standard vaporous naphthalene. The generation of naphthalene takes approximately two hours to stabilize. The vaporous naphthalene in the sampling bulb was adsorbed almost instantly by the solid phase microextraction (SPME) device (Supelco, PDMS [poly(dimethylsiloxane)] coating), which remained exposed for 15 min. The SPME combines the sampling and preconcentration of organic compounds in a single procedure. Naphthalene was directly desorbed into a gas chromatograph (GC) in a heated GC inlet. The SPME device has a structure like a modified syringe that contains a fused silica fiber, which is coated with a $7-\mu \mathrm{m}$ polydimethylsiloxane film as the stationary phase. Naphthalene is analyzed by GC-PID (photon ionization detector, HP 5890 series II). The chromatographic column was a Supelco SPB-5 fused

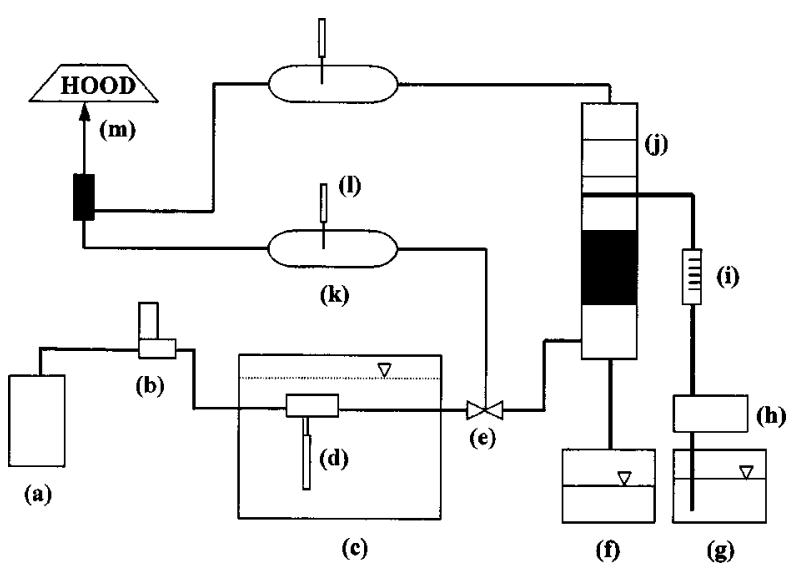

Fig. 1. Illustration of experimental system: (a) pure nitrogen cylinder; (b) mass flow controller; (c) water bath; (d) diffusion tube; (e) switch valve; (f),(g) storage tanks of nonionic surfactant solution; (h) pump; (i) flow meter; (j) packed tower; (k) gas sampling bulb; (l) solid phase microextraction $(\mathrm{m})$ hood 


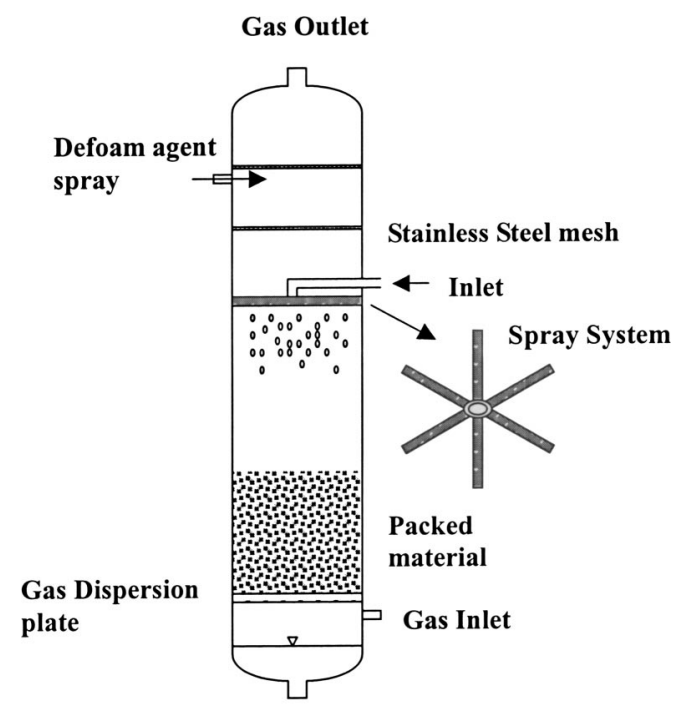

Liquid Outlet

Fig. 2. Illustration of packed tower scrubber

silica capillary column $(30 \mathrm{~m}$ long, $0.53 \mathrm{~mm}$ internal diameter, $1.5 \mu \mathrm{m}$ film thickness). The switch valve was operated to lead the standard vaporous naphthalene into the scrubber after the inlet naphthalene concentration was verified. Nonionic or anionic surfactant solution was stored in a tank and pumped into the scrubber spray apparatus. The flow of the scrubber liquid was controlled using the flow meter. The gas that flowed out of the packed scrubber was sampled using a gas-sampling bulb and analyzed by SPME and GC-PID to determine the concentration of naphthalene.

\section{Design of Packed Tower Scrubber}

The scrubber (Fig. 2) was $80 \mathrm{~cm}$ high and had a diameter of 13 $\mathrm{cm}$; it was made of polymethacrylate resin. The scrubbing liquid was pumped through an inlet and spray apparatus. Gas that included a specified concentration of naphthalene flowed through the gas inlet and the gas dispersion plate. The packed material was of the $1.6 \mathrm{~cm}$ diameter plastic Pall ring type and was made of polyethylene. The surface area was $360 \mathrm{~m}^{2} / \mathrm{m}^{3}$ and the free volume percentage was $83 \%$. The material was packed to a height of $10 \mathrm{~cm}$. The scrubbing liquid and the naphthalene gas were well mixed in the packed material with a liquid/gas ratio of 2.65 $\left(\mathrm{L} / \mathrm{Nm}^{3}\right)$. The mixing time was $7.5 \mathrm{~s}$ and the residence time of the gas was $64.8 \mathrm{~s}$ in the scrubber with the packing material. Two stainless steel meshes were installed to eliminate fog and foam. Whenever too much foaming occurred, an alcoholic defoaming agent was sprayed to suppress it.

\section{Naphthalene Analysis}

Naphthalene was analyzed by GC-PID and SPME. The standard naphthalene concentration was $1,064 \mu \mathrm{g} / \mathrm{nm}^{3}$, generated by a diffusion tube. The coefficient of correlation $R^{2}$ for the calibration curve was 0.998 and the method detection limit (MDL) was 198 $\mu \mathrm{g} / \mathrm{N} \cdot \mathrm{m}^{3}$. The rate of recovery was $92.6-105 \%$. The desorption time for SPME was 2 min in the GC inlet. The GCPID operation parameters were as follows: inlet temperature of $280^{\circ} \mathrm{C}$; detector temperature of $220^{\circ} \mathrm{C}$; oven initial temperature of $80^{\circ} \mathrm{C}$; heating at $15^{\circ} \mathrm{C} / \mathrm{min}$ to $110^{\circ} \mathrm{C}$, at $2.5^{\circ} \mathrm{C} / \mathrm{min}$ to $150^{\circ} \mathrm{C}$, and finally at $20^{\circ} \mathrm{C} /$ $\min$ to $200^{\circ} \mathrm{C}$. The $\mathrm{GC}$ was run for $26.50 \mathrm{~min}$ per sample.
Table 2. Enrichment Factors for Four Surfactants at Different Concentrations

\begin{tabular}{lccc}
\hline & \multicolumn{3}{c}{ Enrichment factor } \\
\cline { 2 - 4 } Concentration $(\mathrm{M})$ & Sodium dodecyl sulfate & $\mathrm{C}_{10} \mathrm{E}_{4}$ & $\mathrm{C}_{14} \mathrm{E}_{8}$ \\
\hline $1.0 \times 10^{-6}$ & - & - & 1.18 \\
$1.0 \times 10^{-5}$ & 1.01 & 1.13 & 1.59 \\
$1.0 \times 10^{-4}$ & 1.03 & 1.37 & 1.67 \\
$1.0 \times 10^{-3}$ & 1.08 & 1.75 & 2.11 \\
$5.0 \times 10^{-3}$ & - & 8.10 & 6.24 \\
$1.0 \times 10^{-2}$ & 1.44 & 14.20 & 12.86 \\
$5.0 \times 10^{-2}$ & 4.68 & - & - \\
$1.0 \times 10^{-1}$ & 9.20 & - & - \\
\hline
\end{tabular}

Note: Taken from Huang 2001.

The experiments involved $\mathrm{C}_{10} \mathrm{E}_{4}$ and $\mathrm{C}_{14} \mathrm{E}_{8}$ surfactant solutions at concentrations of $1.0 \times 10^{-3}, 5.0 \times 10^{-3}$, and $1.0 \times 10^{-2} \mathrm{M}$. The anionic surfactant SDS was used at concentrations of $1.0 \times 10^{-2}, 5.0 \times 10^{-2}$, and $1.0 \times 10^{-1} \mathrm{M}$. All concentrations exceeded the CMC. The scrubber was operated under both continuous and batch conditions. In continuous experiments, the scrubber achieved an approximately steady state after 5 min of operation. The concentration of naphthalene in the flue gas was analyzed in the steady state. In batch experiments, the nonionic surfactant solutions were maintained at a scrubbing liquid volume of $500 \mathrm{~mL}$ without recirculation, and a concentration of $1.0 \times 10^{-2} \mathrm{M}$. The anionic surfactant was present at a scrubbing liquid volume of $500 \mathrm{~mL}$ and a concentration of $1.0 \times 10^{-1} \mathrm{M}$. The concentration of naphthalene in the flue gas was determined at $2,5,8,11$, and $14 \mathrm{~min}$ in the $\mathrm{C}_{10} \mathrm{E}_{4}$ batch experiments. The naphthalene concentration in the flue gas was analyzed at 5, 8, 11, and $14 \mathrm{~min}$ in the $\mathrm{C}_{14} \mathrm{E}_{8}$ batch experiments. The temperature of the scrubbing liquid was about $25^{\circ} \mathrm{C}$. The efficiencies of removal of naphthalene in all reported cases were corrected for the absorption of pure water.

\section{Results and Discussion}

Table 2 summarizes the enrichment factors (EFs) at various concentrations of surfactants (Huang 2001). Our previous studies involved an anionic surfactant (SDS) and two nonionic surfactants $\left(\mathrm{C}_{10} \mathrm{E}_{4}\right.$ and $\left.\mathrm{C}_{14} \mathrm{E}_{8}\right)$ to examine the enhanced solubility of naphthalene in the presence of surfactants (Huang 2001). Experiments on the solubility of vaporous naphthalene at equilibrium in the presence of surfactants were performed to obtain the enrichment factors. The enrichment factor represents the ratio of solubility in the surfactant solution to that in pure water. As the results in Table 2 show, when the concentration of surfactants exceeded the CMC, the enrichment factor was high, and increased with the concentration of surfactants. The CMCs of the two nonionic surfactants are below that of SDS. Consequently, the EFs of the two nonionic surfactants are higher than the EFs of SDS at a given concentration. The data reveal that EFs increase with surfactant concentration, especially in excess of the CMC. Accordingly, the concentrations of the surfactants in the scrubbing liquid in the experiments all exceeded the CMC because the solubility of naphthalene was enhanced mainly at concentrations of surfactants above the CMC.

Table 3 presents the removal efficiency of naphthalene and the absorption capacity in micrograms of naphthalene per gram of surfactant at three concentrations of SDS, $\mathrm{C}_{10} \mathrm{E}_{4}$, and $\mathrm{C}_{14} \mathrm{E}_{8}$. The 
Table 3. Naphthalene Removal Efficiency and Absorption Capacity at Different Concentrations of Surfactants in Continuous Experiments

\begin{tabular}{lccc}
\hline Surfactant & Concentration $(\mathrm{M})$ & $\begin{array}{c}\text { Napthalene removal efficiency }(\%) \\
\text { (corrected for pure water) }\end{array}$ & $\begin{array}{c}\text { Absorption capacity } \\
\text { napthalene/g surfactant) }\end{array}$ \\
\hline Sodium dodecyl sulfate & $1.0 \times 10^{-2}$ & $-6.0 \pm 2.6$ & 8.4 \\
& $5.0 \times 10^{-2}$ & $28.4 \pm 2.7$ & 7.9 \\
$\mathrm{C}_{10} \mathrm{E}_{4}$ & $1.0 \times 10^{-1}$ & $39.0 \pm 1.4$ & 5.4 \\
& $1.0 \times 10^{-3}$ & $52.6 \pm 1.6$ & 631 \\
$\mathrm{C}_{14} \mathrm{E}_{8}$ & $5.0 \times 10^{-3}$ & $66.8 \pm 2.0$ & 760 \\
& $1.0 \times 10^{-2}$ & $59.1 \pm 0.9$ & 90.0 \\
& $1.0 \times 10^{-3}$ & $64.2 \pm 1.2$ & 419 \\
91.0 & 51.0 \\
\end{tabular}

Note: Inlet concentration of naphthalene; $1,064 \mu \mathrm{g} / \mathrm{Nm}^{3}$.

removal efficiency of naphthalene from pure water was 4.3 $\pm 1.9 \%$ under continuous scrubbing. The removal efficiency of naphthalene discussed here is corrected for the value in pure water. Experimental results indicate that the naphthalene removal efficiency increased with the surfactant concentrations over the CMC. The absorption capacity decreased as the concentration of surfactants increased. The efficiencies of removal of naphthalene by $\mathrm{C}_{10} \mathrm{E}_{4}$ and $\mathrm{C}_{14} \mathrm{E}_{8}$ were 75.0 and $71.9 \%$ at a concentration of $1.0 \times 10^{-2} \mathrm{M}$. The removal efficiency of naphthalene by SDS ranged from 6.0 to $39.0 \%$ at a SDS concentration from $1.0 \times 10^{-2}$ to $1.0 \times 10^{-1} \mathrm{M}$. However, the concentrations of SDS were larger than those of $\mathrm{C}_{10} \mathrm{E}_{4}$ and $\mathrm{C}_{14} \mathrm{E}_{8}$; the removal efficiency of naphthalene by SDS was lower than the removal efficiencies by $\mathrm{C}_{10} \mathrm{E}_{4}$ and $\mathrm{C}_{14} \mathrm{E}_{8}$.

Fig. 3 depicts the relationship between the removal efficiency of naphthalene and the surfactant concentration under continuous scrubbing. The results indicate that the removal efficiencies of naphthalene by $\mathrm{C}_{10} \mathrm{E}_{4}$ and $\mathrm{C}_{14} \mathrm{E}_{8}$ were very similar to each other. The removal efficiency of naphthalene by SDS was lower than those by $\mathrm{C}_{10} \mathrm{E}_{4}$ and $\mathrm{C}_{14} \mathrm{E}_{8}$, even though the concentration of SDS exceeded those of $\mathrm{C}_{10} \mathrm{E}_{4}$ and $\mathrm{C}_{14} \mathrm{E}_{8}$. The CMC of SDS exceeded that of $\mathrm{C}_{10} \mathrm{E}_{4}$ and $\mathrm{C}_{14} \mathrm{E}_{8}$, as shown in Table 1. When these three surfactants were at the same concentration, higher than the CMC, more micelles of $\mathrm{C}_{10} \mathrm{E}_{4}$ and $\mathrm{C}_{14} \mathrm{E}_{8}$ were formed than of SDS. Accordingly, more micelle cores were available to capture the naphthalene in the $\mathrm{C}_{10} \mathrm{E}_{4}$ and $\mathrm{C}_{14} \mathrm{E}_{8}$ scrubbing liquid than in the

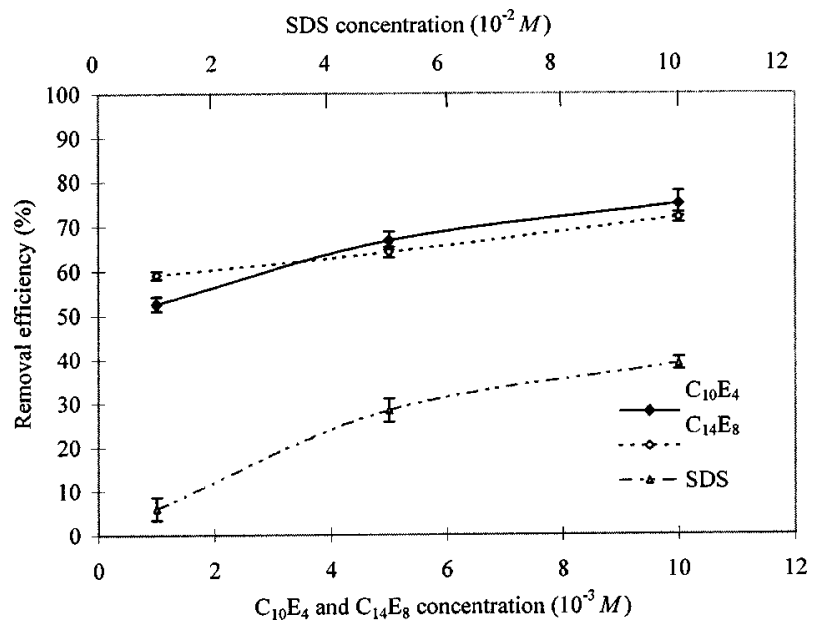

Fig. 3. Removal efficiency of naphthalene as a function of concentrations of surfactants (sodium dodecyl sulfate, $\mathrm{C}_{10} \mathrm{E}_{4}$, and $\mathrm{C}_{14} \mathrm{E}_{8}$ ) at 2.65 liquid/gas ratio
SDS scrubbing liquid. As Table 3 states, the absorption capacity was negatively correlated with the concentration of surfactants and with the removal efficiency of naphthalene. The SDS had the lowest absorption capacity. The absorption capacity declined as the concentration of surfactant increased, because the enhanced dosage of surfactant exceeded the enhanced efficiency of removal of naphthalene. Therefore, the absorption capacity at high efficiency can be enhanced if the scrubbing liquid can be recycled, reducing the removal efficiency of naphthalene.

Table 4 presents the concentrations of effluent naphthalene and the removal efficiencies at various absorption times in batch experiments. The time to breakthrough was approximately $14-17$ min in batch experiments that involved SDS, $\mathrm{C}_{10} \mathrm{E}_{4}$, and $\mathrm{C}_{14} \mathrm{E}_{8}$. The batch experiments involved $500 \mathrm{~mL}$ of scrubbing liquid without recirculation, and a SDS concentration of $1.0 \times 10^{-1} \mathrm{M}$, a $\mathrm{C}_{14} \mathrm{E}_{8}$ concentration of $1.0 \times 10^{-2} \mathrm{M}$, and a $\mathrm{C}_{10} \mathrm{E}_{4}$ concentration of $1.0 \times 10^{-2} \mathrm{M}$. The batch absorption capacity of naphthalene was $2.4 \mu \mathrm{g} \mathrm{Nap} / \mathrm{g}$ SDS, $31.8 \mu \mathrm{g} \mathrm{Nap} / \mathrm{g} \mathrm{C}_{10} \mathrm{E}_{4}$, and $12.9 \mu \mathrm{g} \mathrm{Nap} / \mathrm{g}$ $\mathrm{C}_{14} \mathrm{E}_{8}$, as determined from the total amount of naphthalene trapped during the period of absorption.

The data provided here imply that the removal efficiency of naphthalene by $\mathrm{C}_{10} \mathrm{E}_{4}$ and $\mathrm{C}_{14} \mathrm{E}_{8}$ exceeded that of SDS. Furthermore, $\mathrm{C}_{10} \mathrm{E}_{4}$ and $\mathrm{C}_{14} \mathrm{E}_{8}$ yielded similar removal efficiencies. The efficiency was over $70 \%$ for $\mathrm{C}_{10} \mathrm{E}_{4}$ and $\mathrm{C}_{14} \mathrm{E}_{8}$ at $1.0 \times 10^{-2} \mathrm{M}$ in continuous experiments. The capacity of $\mathrm{C}_{10} \mathrm{E}_{4}$ to absorb naphthalene was approximately 2.5 times greater than that of $\mathrm{C}_{14} \mathrm{E}_{8}$ in batch scrubbing. The chemical structure of molecular $\mathrm{C}_{10} \mathrm{E}_{4}$ consists of a ten-carbon chain and four polyoxyethylene groups. $\mathrm{C}_{14} \mathrm{E}_{8}$ is composed of a 14-carbon chain and eight polyoxyethylene groups. The carbon chain is the hydrophobic end and the polyoxyethylene is the hydrophilic end. A longer carbon chain corresponds to greater hydrophobicity. In contrast, more polyoxyethylene groups correspond to higher hydrophilicity. Both the carbon chain and polyoxyethylene groups in $\mathrm{C}_{14} \mathrm{E}_{8}$ are longer than those in $\mathrm{C}_{10} \mathrm{E}_{4}$. Therefore, the strengths of the hydrophobic and hydrophilic properties of $\mathrm{C}_{10} \mathrm{E}_{4}$ and $\mathrm{C}_{14} \mathrm{E}_{8}$ are difficult to compare. The difference between the absorption capacities of $\mathrm{C}_{10} \mathrm{E}_{4}$ and that of $\mathrm{C}_{14} \mathrm{E}_{8}$ can be explained by the hydrophile-lipophile balance (HLB) value, as defined by Griffin (Rosen 1989), to represent the overall characteristics of the balance between the hydrophilic and lipophilic interactions. For nonionic surfactants, the HLB value is defined as

$$
\mathrm{HLB}=\frac{M_{H}}{M_{H}+M_{L}} \times 20
$$

The term $M_{H}$ represents the molecular weight of the hydrophilic segment and $M_{L}$ is the molecular weight of the lipophilic segment in a nonionic surfactant molecule. The calculated HLB values of 
Table 4. Naphthalene Outflow Concentration and Removal Efficiency by Surfactants at Various Absorption Times in Batch Experiments

\begin{tabular}{|c|c|c|c|}
\hline Surfactant & Absorption time (min) & Napthalene outflow concentration $\left(\mu \mathrm{g} / \mathrm{nm}^{3}\right)$ & Removal efficiency $(\%)$ \\
\hline \multirow[t]{5}{*}{ Sodium dodecyl sulfate } & 5 & 677 & 36.4 \\
\hline & 8 & 683 & 35.8 \\
\hline & 11 & 719 & 32.5 \\
\hline & 14 & 842 & 21.0 \\
\hline & 17 & 1,060 & 0 \\
\hline \multicolumn{4}{|c|}{ Batch absorption capacity of naphthalene $2.4 \mu \mathrm{g}$ Nap/g SDS } \\
\hline \multirow[t]{5}{*}{$\mathrm{C}_{10} \mathrm{E}_{4}$} & 2 & 398 & 62.7 \\
\hline & 5 & 554 & 48.0 \\
\hline & 8 & 609 & 42.8 \\
\hline & 11 & 616 & 42.2 \\
\hline & 14 & 1,021 & 4.1 \\
\hline \multicolumn{4}{|c|}{ Batch absorption capacity of naphthalene $31.8 \mu \mathrm{g} \mathrm{Nap} / \mathrm{g} \mathrm{C}_{10} \mathrm{E}_{4}$} \\
\hline \multirow[t]{4}{*}{$\mathrm{C}_{14} \mathrm{E}_{8}$} & 5 & 447 & 58.0 \\
\hline & 8 & 678 & 36.3 \\
\hline & 11 & 844 & 20.7 \\
\hline & 14 & 1,063 & 0 \\
\hline
\end{tabular}

Batch absorption capacity of naphthalene $12.9 \mu \mathrm{g} \mathrm{Nap} / \mathrm{g} \mathrm{C}_{14} \mathrm{E}_{8}$

Notes: The inlet concentration of naphthalene was $1,064 \mu \mathrm{g} / \mathrm{nm}^{3}$. The concentration of SDS was $1.0 \times 10^{-1} \mathrm{M}$. The concentrations of $\mathrm{C}_{10} \mathrm{E}_{4}$ and $\mathrm{C}_{14} \mathrm{E}_{8}$ were $1.0 \times 10^{-2} \mathrm{M}$.

$\mathrm{C}_{10} \mathrm{E}_{4}$ and $\mathrm{C}_{14} \mathrm{E}_{8}$ were 11.56 and 14.47 , respectively. A higher $\mathrm{HLB}$ value implies a more hydrophilic nature. Accordingly, $\mathrm{C}_{10} \mathrm{E}_{4}$ is more hydrophobic than $\mathrm{C}_{14} \mathrm{E}_{8}$. The $\mathrm{C}_{10} \mathrm{E}_{4}$ solution dissolves more of a hydrophobic organic compound, such as naphthalene, than does $\mathrm{C}_{14} \mathrm{E}_{8}$.

This study involved a laboratory-scale packed tower scrubber to explore a control technology that can be applied to remove vaporous PAHs from flue gases emitted from municipal incinerators. This work considered a municipal waste incinerator plant in Taiwan. The design and operating parameters of the laboratoryscale scrubber were based on the scrubber at this plant. The experimental removal efficiency and capacity were used to determine the amounts of surfactant required and the cost of the surfactant consumed. Some quotations for industrial-grade chemicals on the Taiwanese market were requested to estimate the costs of the surfactants for removing gram quantities of naphthalene. Pure nonionic surfactants were substituted for industrial-grade nonionic surfactants with the fatty alcohol polyethylene glycol ether group. Pannox 77 is similar to $\mathrm{C}_{10} \mathrm{E}_{4}$, and the two substances have a very close HLB value. Pannox 79 is very similar to $\mathrm{C}_{14} \mathrm{E}_{8}$. Pannox is a trademark of the Pan Asia Chemical Corporation. The surfactant prices were $\$ 3.6$ per $\mathrm{kg}$ for SDS, $\$ 1.5$ per $\mathrm{kg}$ for Pannox 77, and $\$ 1.7$ per kg for Pannox 79. The surfactant costs per gram of naphthalene removed were estimated from the absorption capacity and surfactant prices. The results reveal that less $\mathrm{C}_{10} \mathrm{E}_{4}$ than $\mathrm{SDS}$ or $\mathrm{C}_{14} \mathrm{E}_{8}$ was consumed. Table 5 summarizes the assessed costs of the surfactants added to the scrubbing liquid. Other items examined were efficiency, absorption capacity, available concentration range, effect of foaming, and impact of wastewater. The impact of wastewater was determined from the dose of surfactant added, the amount of wastewater processed daily in a plant, and the biological oxygen demand (BOD) contribution of surfactants, to obtain the contribution to BOD by surfactants in the wastewater system of a plant. The contribution by surfactants to BOD was assumed to be completely biodegradable, and estimated as $1.61 \mathrm{~g} \mathrm{BOD} / \mathrm{g} \mathrm{SDS}, 2.39 \mathrm{~g} \mathrm{BOD} / \mathrm{g} \mathrm{C}_{10} \mathrm{E}_{4}$, and $2.31 \mathrm{~g}$ $\mathrm{BOD} / \mathrm{g} \mathrm{C}_{14} \mathrm{E}_{8}$. The results suggest that nonionic surfactants such as $\mathrm{C}_{10} \mathrm{E}_{4}$ and $\mathrm{C}_{14} \mathrm{E}_{8}$ are preferred over the anionic surfactant SDS, and that $\mathrm{C}_{10} \mathrm{E}_{4}$ is better than $\mathrm{C}_{14} \mathrm{E}_{8}$ for addition to the scrubbing liquid to remove vaporous PAHs from flue gas emitted from municipal waste incinerators.

\section{Conclusions}

This investigation considered the removal of a representative $\mathrm{PAH}$, naphthalene, using a wet scrubber, by adding nonionic and anionic surfactants to the scrubbing liquid. Nonionic surfactants $\left(\mathrm{C}_{10} \mathrm{E}_{4}\right.$ and $\left.\mathrm{C}_{14} \mathrm{E}_{8}\right)$ and the anionic surfactant SDS were added at concentrations higher than the CMC. The hydrophobic inner core

Table 5. Overall Assessment of Surfactants

\begin{tabular}{|c|c|c|c|}
\hline Item & Sodium dodecyl sulfate & $\mathrm{C}_{10} \mathrm{E}_{4}$ & $\mathrm{C}_{14} \mathrm{E}_{8}$ \\
\hline Removal efficiency $(\eta)$ & $6.0-39.0 \%$ & $52.6-75.0 \%$ & $59.1-71.9 \%$ \\
\hline Absorption capacity ( $\mu \mathrm{g} \mathrm{Nap/g} \mathrm{surfactant)} \mathrm{(at} \mathrm{concentration} 10^{-2} \mathrm{M}$ ) & 8.4 & 90.0 & 51.0 \\
\hline Concentration & $10^{-1} \mathrm{M}$ & $10^{-3}-10^{-2} \mathrm{M}$ & $10^{-3}-10^{-2} \mathrm{M}$ \\
\hline Cost (\$/g Nap) & 428 & 16.7 & 33.3 \\
\hline (industrial grade chemical) & $\eta(39 \%)$ & $\eta(75 \%)$ & $\eta(71 \%)$ \\
\hline Foaming (by observation) & High & Low & Medium \\
\hline Wastewater impact, BOD contribution & $\eta(39 \%)$ & $\eta(70 \%)$ & $\eta(70 \%)$ \\
\hline mg BOD/L & 2.6 & 0.31 & 0.64 \\
\hline g BOD/mg Nap removed & 193 & 18.0 & 37.9 \\
\hline
\end{tabular}


of micelles formed above the CMC increases the solubility of naphthalene. The efficiency of removal of naphthalene by both nonionic surfactants $\mathrm{C}_{10} \mathrm{E}_{4}$ and $\mathrm{C}_{14} \mathrm{E}_{8}$ exceeds $70 \%$ at a surfactant concentration of $1.0 \times 10^{-2} \mathrm{M}$ with continuous scrubbing. The absorption capacity of $\mathrm{C}_{10} \mathrm{E}_{4}$ with continuous scrubbing was higher than that of $\mathrm{C}_{14} \mathrm{E}_{8}$ and SDS at a given concentration. In batch experiments, the total capacity of $\mathrm{C}_{10} \mathrm{E}_{4}$ to absorb naphthalene was 2.5 times higher than that of $\mathrm{C}_{14} \mathrm{E}_{8}$. The HLB values of $\mathrm{C}_{10} \mathrm{E}_{4}$ and $\mathrm{C}_{14} \mathrm{E}_{8}$ were determined to be 11.56 and 14.47, respectively, implying that $\mathrm{C}_{10} \mathrm{E}_{4}$ is more hydrophobic than $\mathrm{C}_{14} \mathrm{E}_{8}$. Overall, of the three surfactants considered here, $\mathrm{C}_{10} \mathrm{E}_{4}$ is the best surfactant to be added to scrubbing liquid for removing vaporous naphthalene. The data imply that control of the vaporous PAHs in flue gas from municipal waste incinerators using a wet scrubber is feasible if appropriate surfactants are added to the scrubbing liquid. However, future research should address the removal of other PAH compounds present at low concentrations, but which are more complex and toxic than naphthalene.

\section{Acknowledgment}

The writers would like to thank the Bureau of Environmental Protection, Taipei Municipal Government of the Republic of China, for funding this study.

\section{References}

An, Y. J., Carraway, E. R., and Schlautman, M. A. (2002). “Solubilization of polycyclic aromatic hydrocarbons by perfluorinated surfactant micelles." Water Res., 36(1), 300-308.

Bai, D. S., Li, J. L., Chen, S. B., and Chen, B. H. (2001). "A novel cloud-point extraction process for preconcentrating selected polycyclic aromatic hydrocarbons in aqueous solution." Environ. Sci. Technol., 35(19), 3936-3940.

Butler, E. C., and Hayes, K. F. (1998). "Micellar solubilization of nonaqueous phase liquid contaminants by nonionic surfactant mixtures: Effects of sorption, partitioning and mixing." Water Res., 32(5), 1345-1354.

Chen, L. J., Lin, S. Y., Huang, C. C., and Chen, E. M. (1998). “Temperature dependence of critical micelle concentration of polyoxyethylenated nonionic surfactants." Colloids Surf., A, 135, 178-181.

Clarke, A. N., Oma, K. H., Megehee, M. M., and Wilson, D. J. (1993). "Soil cleanup by surfactant washing. II. Design and evaluation of the components of the pilot-scale surfactant recycle system." Sep. Sci. Technol., 28, 2103-2135.

Doong, R. A., Lei, W. G., Chen, T. F., Lee, C. Y., Chen, J. H., and Chang, W. H. (1996). "Effect of anionic and nonionic surfactants of sorption and micellar solubilization of monocyclic aromatic compounds." Water Sci. Technol., 34, 327-334.

Edwards, D. A., Liu, Z., and Luthy, R. G. (1992). "Interactions between nonionic surfactant monomers, hydrophobic organic compounds and soil." Water Sci. Technol., 26(1-2), 147-158.

Edwards, D. A., Luthy, R. G., and Liu, Z. (1991). "Solubilization of polycyclic aromatic hydrocarbons in micellar nonionic surfactant so- lutions." Environ. Sci. Technol., 25(1), 127-133.

Guha, S., Jaffé, P. R., and Peters, C. A. (1998a). "Bioavailability of mixtures of PAHs partitioned into the micellar phase of a nonionic surfactant." Environ. Sci. Technol., 32(5), 2317-2324.

Guha, S., Jaffé, P. R., and Peters, C. A. (1998b). "Solubilization of PAH mixtures by a nonionic surfactant." Environ. Sci. Technol., 32(7), 930-935.

Huang, H. L. (2001). "Study on control of vaporous polycyclic aromatic hydrocarbons using surfactants." $\mathrm{PhD}$ thesis, Graduate Institute of Environmental Engineering, National Taiwan Univ., Taipei, Taiwan.

Huang, H. L., and Lee, W.-M. G. (2002). "Simultaneous removal of naphthalene and sulfur dioxide using surfactant." J. Environ. Eng., $128(1), 60-67$.

Link, A. (2000). "Effect of nonionic surfactants on dissolution of polycyclic aromatic hydrocarbons from coal tar." Pract. Period. Hazard., Toxic, Radioact. Waste Manage., 4(2), 78-81.

Liu, G. G., and Roy, D. (2000). "A simple method to estimate the surfactant micelle-water distribution coefficients of aromatic hydrocarbons." Langmuir, 16(8), 3595-3605.

Liu, Z., Laha, S., and Luthy, R. G. (1991). "Surfactant solubilization of polycyclic aromatic hydrocarbon compounds in soil-water suspensions." Water Sci. Technol., 23, 475-485.

Paterson, I. F., Chowdhry, B. Z., and Leharne, S. A. (1999). "Polycyclic aromatic hydrocarbon extraction from a coal tar contaminated soil using aqueous solution of nonionic surfactants." Chemosphere, 38(13), 3095-3107.

Rosen, M. J. (1989). Surfactants and interfacial phenomena, Wiley, New York.

Shiau, B. J., Sabatini, D. A., and Harwell, J. H. (2000). "Chlorinated solvent removal using food grade surfactants: Column studies." $J$. Environ. Eng., 126(7), 611-621.

Tiehm, A., Stieber, M., Werner, P., and Frimmel, F. H. (1997). "Surfactant-enhanced mobilization and biodegradation of polycyclic aromatic hydrocarbons in manufactured gas plant soil." Environ. Sci. Technol., 31, 2570-2576.

Vipulanandan, C., and Ren, X. P. (2000). "Enhanced solubility and biodegradation of naphthalene with biosurfactant." J. Environ. Eng. (Reston, Va.), 126(7), 629-634.

Yang, H. H., Lee, W. J., Chen, S. J., and Lai, S. O. (1998). "PAH emission from various industrial stacks." J. Haz. Mat., 60, 159-174.

Yeom, I. T., Ghosh, M. M., and Cox, C. D. (1996). "Kinetic aspects of surfactant solubilization of soil-bound polynuclear aromatic hydrocarbons." Environ. Sci. Technol., 30, 1589-1595.

Yeom, I. T., Ghosh, M. M., Cox, C. D., and Robinson, K. G. (1995). "Micellar solubilization of polynuclear aromatic hydrocarbons in coal tar contaminated soils.” Environ. Sci. Technol., 29(12), 3015-3021.

You, J. H., Chiang, P. C., and Chang, S. C. (1994). "Polycyclic aromatic hydrocarbons and mutagenicity of soot particulates in air emissions from the two-stage incineration of polystyrene." J. Haz. Mat., 36, $1-17$.

Zheng, Z. M., and Obbard, J. P. (2000). "Removal of polycyclic aromatic hydrocarbons from soil using surfactant and the white rot fungus Phanerochaete chrysosporium." J. Chem. Technol. Biotechnol., 75(12), 1183-1189.

Zheng, Z. M., and Obbard, J. P. (2002). "Evaluation of an elevated nonionic surfactant critical micelle concentration in a soil/aqueous system." Water Res., 36(10), 2667-2672. 